\title{
¡Exijo una explicación!: El deber de motivar debidamente las desestimaciones de las propuestas de Iniciativas Privadas
}

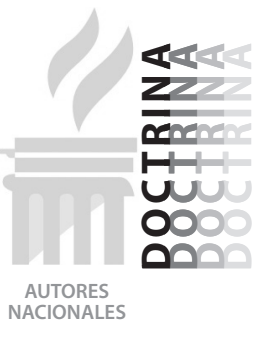

\begin{abstract}
José Francisco León Pacheco*
Abogado por la Pontificia Universidad Católica del Perú. Estudios de Postgrado en Derecho de la Construcción y Derecho de las Concesiones en la Universidad Peruana de Ciencias Aplicadas. Egresado de la Maestría en Regulación con mención en Infraestructura y Concesiones de la Universidad Peruana de Ciencias Aplicadas.
\end{abstract}

SUMARIO:

I. Introducción.

II. Consideraciones Generales respecto de la relevancia de las Iniciativas Privadas.

III. ¿Qué implica que una iniciativa privada sea calificada como petición de gracia?

IV. La desestimación de una iniciativa privada sin una debida motivación, con figura una vulneración al "debido proceso de promoción de la inversión privada".

Abogado Asociado del Estudio Benites, Forno, Ugaz \& Ludowieg, Andrade. 


\section{INTRODUCCIÓN}

El ejercicio de la profesión me ha permitido una aproximación a diversos procesos de promoción de la inversión privada; en algunos casos, asesorando a inversionistas privados, en otros, a Organismos de Promoción de la Inversión Privada.

El presente trabajo tiene como finalidad compartir algunas reflexiones surgidas a partir de tales experiencias, con relación, por un lado, a la relevancia de las Iniciativas Privadas como mecanismo para la promoción de la inversión privada y como importante herramienta para la reducción de la brecha de infraestructura en el Perú; y, por el otro, a la importancia de que la decisión de un Organismo Promotores de la Inversión Privada de no llevar a cabo un proyecto propuesto bajo una Iniciativa Privada se encuentre debidamente motivada, más aún cuando durante su evaluación siempre se encontrarán involucrados factores circunstanciales, coyunturales o de naturaleza distinta a los fundamentos jurídicos, financieros, económicos, técnicos y/o medio ambientales, entre otros.

\section{CONSIDERACIONES GENERALES RESPECTO DE LA RELEVANCIA DE LAS INICIATIVAS PRIVADAS}

En distintas investigaciones y documentos de trabajo se ha reconocido la existencia de una relación positiva entre la inversión para la provisión de infraestructura, la reducción de la pobreza, el crecimiento económico y la competitividad'. Sin duda, contar con un nivel adecuado de infraestructura y servicios públicos (transporte, saneamiento, comunicaciones, energía, entre otros) constituye un factor esencial para el crecimiento y la compe- titividad de los países. Asimismo, tiene efectos en la reducción de la pobreza y en la mejora de la calidad de vida de los pobladores, debido a que permite la integración de zonas de difícil acceso y la modernización de los servicios que reciben los usuarios.

Lo anterior puede ser explicado a través del gráfico ${ }^{2}$ que se presenta a continuación

Según lo señalado en el Reporte de Competitividad Global del Foro Económico Mundial (20102011), si bien el Perú ha mejorado 11 posiciones en el ranking global de competitividad en infraestructura con respecto al reporte 2009-2010, actualmente viene ocupando el lugar 88 de un total de 1390 países. Ello, revela que nuestro país se encuentra muy por detrás de otros en Sudamérica, tales como Chile (puesto 40), Brasil (puesto 62) y Colombia (puesto 79). En tal sentido, resulta evidente que existe una importante demanda por proyectos de infraestructura a fin de cerrar la brecha de infraestructura y, por ende, una mayor demanda por recursos públicos para poder llevar a cabo estos proyectos, operarlos y darles mantenimiento ${ }^{3}$.

No obstante, la reconocida importancia del desarrollo de la infraestructura, los recursos públicos disponibles no resultan suficientes para satisfacer las presiones de la demanda de proyectos de infraestructura. Ello, conlleva a que la mayoría de países en desarrollo recurra al sector privado para financiar y gestionar los servicios de infraestructura, en busca de las inversiones y la idoneidad (know-how) necesarios para acelerar las mejoras en los niveles y calidad del servicio ${ }^{4}$.

Precisamente, las Iniciativas Privadas constituyen un mecanismo o modalidad para la partici-

1. Cfr. LUCIONI, Luis. La inversión para la provisión de servicios públicos y su financiamiento en América Latina y el Caribe: evolución reciente, situación actual y políticas. CEPAL: Santiago de Chile, 2004. p.5. Igualmente, PERROTI, Daniel E. y SÁNCHEZ, Ricardo J. La brecha de infraestructura en América Latina y el Caribe. CEPAL: Santiago de Chile, 2011. pp. 7-13.

2. ROZAS, Patricio y SÁNCHEZ, Ricardo. Desarrollo de Infraestructura y Crecimiento Económico: revisión conceptual. CEPAL: Santiago de Chile, 2004. p. 40.

3. Informe Preelectoral Administración 2006-2001, publicado el 10 de enero de 2011 en el Diario Oficial "El Peruano".

4. GUASCH, José Luis. Concesiones en Infraestructura. Cómo hacerlo bien. Antoni Bosch Editor: Barcelona, 2005. p. 25. 


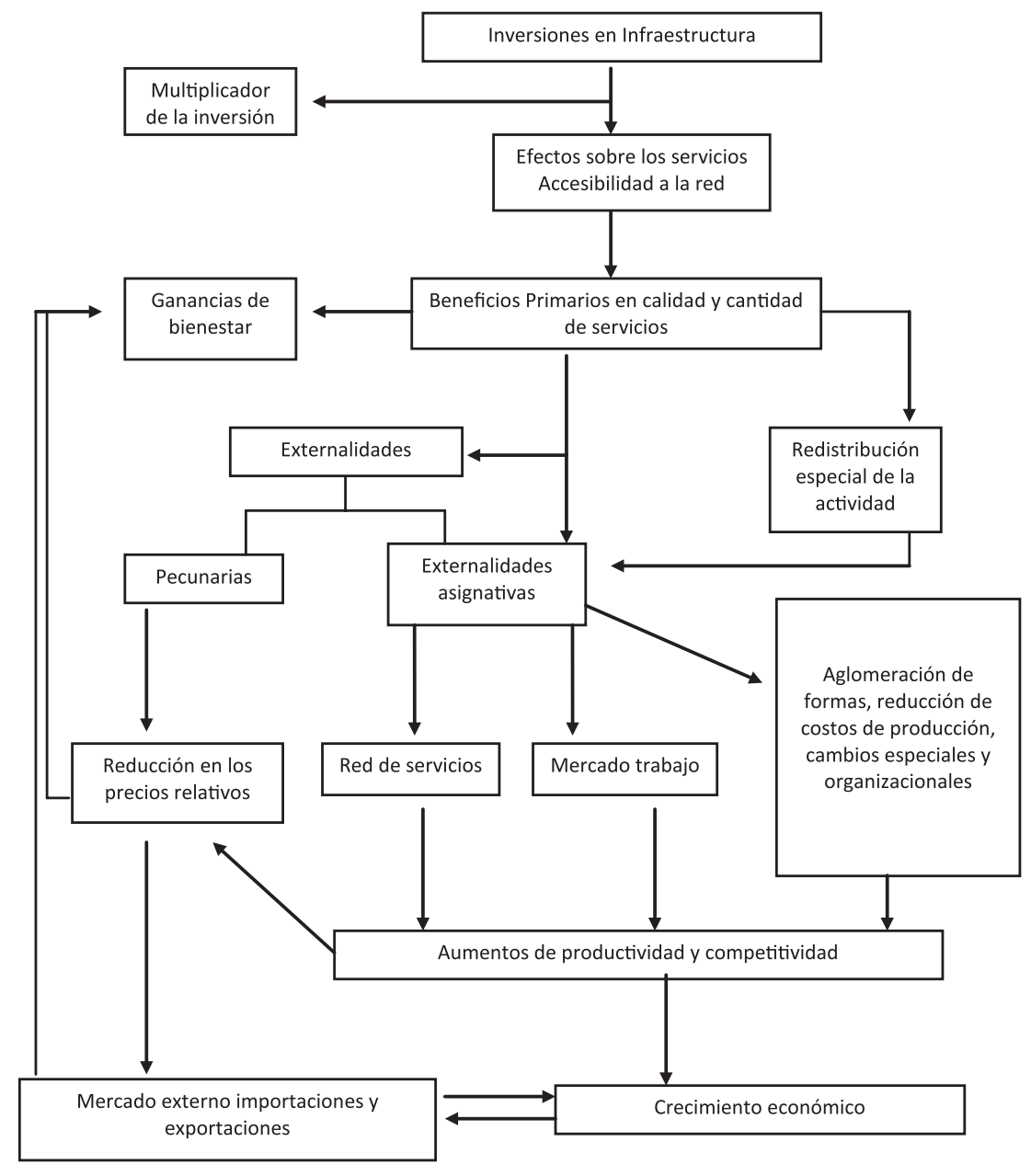

pación o promoción de la inversión privada, a través del cual una persona jurídica del sector privado (nacional o extranjera) propone a un Organismo Promotor de la Inversión Privada (en adelante, OPIP), en cualquiera de los niveles de gobierno del Estado (Nacional, Regional o Local), el desarrollo de un innovador proyecto de inversión en activos, empresas, proyectos, servicios, obras públicas de infraestructura y de servicios públicos ${ }^{5}$. Con relación a esto último, MORI COCKBURN considera que debe tratarse de una idea de negocio con un importante grado de definición ${ }^{6}$.

Un sector importante de la doctrina reconoce que, desde su perspectiva sustantiva, la Iniciativa Privada tiene cabida en la fase previa prenegocial o preparatoria, y aparece como una forma de tratativa preliminar entre el proponente y el OPIP competente a fin de analizar la propuesta y definir la existencia o no de interés general en el negocio, de cara a un eventual contrato de contenido público. En suma, la Iniciativa Privada provoca una negociación preliminar que permite al proponente colaborar en la identificación, diseño y concertación del objeto de un probable contrato con el Estado?.

5. Lo indicado resulta coincidente con la definición de Iniciativa Privada, prevista en el artículo 14 del Decreto Legislativo 1012, que aprueba la Ley Marco de Asociaciones Público - Privadas.

6. MORI COCKBURN, Javier. Iniciativas Privadas y Proyectos de Inversión. En: Revista de Derecho Administrativo. Año III. Número 04. Lima, Enero 2008. p. 246.

7. MORÓN URBINA, Juan Carlos. Las Concesiones de Infraestructura a Iniciativa del Inversionista. En: Revista Peruana de Derecho Administrativo Económico. Infraestructura, contratos, servicios públicos e inversión. Promoción de la Inversión Privada: Concesión y servicios públicos. No. 2. Editorial Jurídica Grijley: Lima, 2007. p. 157. 
De otro lado, es igualmente reconocido en doctrina que las propuestas bajo la modalidad de una Iniciativa Privada resultan de gran importancia para el incremento de la inversión privada en los países en vías de desarrollo, toda vez que la elaboración de los lineamientos básicos de los proyectos por parte de los particulares, implica un significativo ahorro de tiempo y de fondos públicos para el Estado, el cual normalmente elabora un conjunto de bases administrativas complejas e incompletas, y cuyo sustento técnico es cuestionado en la mayoría de los casos, por los propios inversionistas privados. De este modo, las Iniciativas Privadas facilitan al sector privado el desarrollo de proyectos que no han podido ser identificados por el Estado8.

En efecto, a través de las Iniciativas Privadas, los integrantes de la comunidad pueden participar en la labor de identificar y proponer al Estado estudios sobre posibilidades innovadoras de infraestructura, servicios públicos o emprendimientos sobre recursos públicos, que siendo de interés empresarial del proponente, también pueden ser prioritarios para el interés público, esto es, proyectos socialmente rentables, sostenibles y concordantes con las políticas y lineamientos del Estado. Así, se fomenta que los particulares colaboren en la identificación de prioridades $y$, en general, capten ideas innovadoras relacionadas con la explotación de un proyecto de inversión, las que, como todo emprendimiento empresarial, basarán su desarrollo en la relación costo-beneficio?.

Sobre el particular, RUFIÁN LIZANA sostiene lo siguiente:

"Aunque la iniciativa privada en materia de concesión no es una figura original de la legislación chilena, esta figura ha tenido en Chile una enorme trascendencia debido al gran número de iniciativas presentadas y aprobadas por el Ministerio, algunas de las cuales han sido ya adjudicadas probablemente por el incentivo establecido de premiar la idea de iniciativa privada en la misma licitación de la concesión. (...)

El requisito para que un particular pueda presentar un proyecto de concesión es que esta obra no esté, en el momento de su presentación, siendo estudiada por el MOP [Ministerio de Obras Públicas] para ser ejecutada por el mismo sistema. Puesto que en el momento de aprobación del reglamento el Ministerio aún no había preparado una cartera de proyectos concesionables, por ser muy reciente la Ley de Concesiones, el sistema de iniciativas privadas ha tenido un gran éxito durante los primeros años de funcionamiento del sistema y ha permitido incorporar obras al sistema de concesión de una gran trascendencia que, probablemente hubieran podido ser incorporadas directamente por el MOP. En el futuro, con una cartera de proyectos concesionables en el Ministerio, el sistema de iniciativas privadas adquirirá su pleno sentido al proponer obras que, por su naturaleza y características, no hubieran podido ser propuestas por el Ministerio"110. [el subrayado es nuestro]

De este modo, las propuestas de proyectos de inversión que sean formuladas por el sector privado, podrán encontrarse relacionadas, entre otros aspectos, "con la prestación de servicios públicos (telecomunicaciones, electricidad, saneamiento, limpieza pública, entre otros), o aquellos que deban ser implementados en terrenos de propiedad estatal o que involucren la utilización de bienes públicos, como puede ser el caso de proyectos inmobiliarios, de regadío, agrícolas, entre

8. MARTIN TIRADO, Richard. Las Iniciativas Privadas en el proceso de promoción de la inversión privada en el Perú. En: Revista Peruana de Derecho Administrativo Económico. Infraestructura, contratos, servicios públicos e inversión. Promoción de la Inversión Privada: Concesión y servicios públicos. No. 2. Editorial Jurídica Grijley: Lima, 2007. pp. 19-22.

9. MORÓN URBINA, Juan Carlos. Op.Cit. pp. 150-151.

10. RUFIÁN LIZANA, Dolores M. Manual de Concesiones de Obras Públicas. Fondo de Cultura Económica: Santiago de Chile, 1999. pp. 36-37. 
otros que se pretenda ejecutar sobre o en relación con bienes de tal naturaleza"11. Sin embargo, una Iniciativa Privada, no solo deberá suponer el desarrollo de un proyecto rentable y sostenible, acondicionado o creado en concordancia con las políticas y lineamientos del Estado; sino también deberá contener un cálculo de costos y beneficios para el agente privado que presenta la propuesta, y ser del interés del Estado ${ }^{12}$.

Finalmente, no podemos dejar de mencionar que, a nuestra consideración, los proyectos de inversión formulados bajo la modalidad de Iniciativa Privada deben caracterizarse por ser innovadores ${ }^{13}$, opinión que es compartida por un importante sector de la doctrina ${ }^{14}$. Precisamente, sobre el carácter innovador de las Iniciativas Privadas, resulta pertinente lo señalado por FARINELLI:

"Cuando el Estado sabe lo que quiere y cómo lo quiere, Ilama a licitación pública; cuando sabe lo que quiere pero no cómo lo quiere llama a un concurso de proyectos integrales; cuando no sabe lo que quiere ni cómo lo quiere, llama a la presentación de iniciativas"15.

\section{III. ¿QUÉ IMPLICA QUE UNA INICIATIVA PRIVADA SEA CALIFICADA COMO PETICIÓN DE GRACIA?}

Previamente a abordar con detalle el tema propuesto en la presente sección, consideramos relevante tener presente que la petición de gracia constituye una de las modalidades a través de las cuales se ejerce el derecho fundamental de petición, reconocido expresamente en el inciso 20) del artículo $2^{16}$ de la Constitución.

Con relación al referido derecho fundamental, GARCÍA TOMA ${ }^{17}$ lo define como el reconocimiento que el Estado hace a cada persona, para poder dirigirse por escrito y directamente a una autoridad pública, con el objeto de solicitarle alguna acción vinculada con su quehacer funcional. Asimismo, indica que en doctrina se expone que la facultad de petición se ejerce individual o colectivamente, quedando sujeta por lo general a la consideración discrecional del titular de un órgano investido de autoridad pública.

Por su parte, SALAZAR CHÁVEZ ${ }^{18}$ lo considera como el derecho de toda persona que no es

11. MORI COCKBURN, Javier. Op.Cit. pp. 236-237.

12. VIVANCO DEL CASTILLO, Tábata y VILLANUEVA LLAQUE, Augusto. Iniciativas Privadas: avances de esta modalidad de promoción de la inversión privada. En: Revista Peruana de Derecho Administrativo Económico. Infraestructura, contratos, servicios públicos e inversión. Promoción de la Inversión Privada: Concesión y servicios públicos. Número 2. Editorial Jurídica Grijley: Lima, 2007. p. 304.

13. Sobre el particular, si bien las disposiciones específicas previstas en el Decreto Legislativo 1012, que aprueba la Ley Marco de Asociaciones Público-Privadas, y su Reglamento, aprobado mediante Decreto Supremo 146-2008$\mathrm{EF}$, no contemplan como requisito que los proyectos de inversión propuestos bajo la modalidad de Iniciativas Privadas deban ser innovadores; el inciso e) del artículo 16 del Reglamento de la Ley Marco de Inversión Descentralizada - Ley 28059, aprobado mediante Decreto Supremo 015-2004-PCM, establece que dicha característica constituye un criterio a ser tomado en cuenta por la OPIP competente para la evaluación de una Iniciativa Privada.

14. MORÓN URBINA, Juan Carlos. Op.Cit. pp. 165-168.

15. FARINELLI EVANS, Guillermo. Concesión. En: Revista Argentina del Régimen de la Administración Pública. Buenos Aires: Noviembre, 1993. p. 104.

16. "Artículo $2^{\circ}$.- Toda persona tiene derecho:

(...)

20. A formular peticiones, individual o colectivamente, por escrito ante la autoridad competente, la que está obligada a dar al interesado una respuesta también por escrito dentro del plazo legal, bajo responsabilidad.

Los miembros de las Fuerzas Armadas y de la Policía Nacional solo pueden ejercer individualmente el derecho de petición".

17. GARCÍA TOMA, Víctor. Los Derechos Fundamentales en el Perú. Jurista Editores: Lima, 2008. p. 264.

18. SALAZAR CHÁVEZ, Ricardo. El Derecho de Petición y la Administración Pública en el Perú. En: Themis. Revista de Derecho. No. 39, 1999. p. 190. 
titular de derechos subjetivos o de intereses legítimos, de dirigir peticiones a los organismos, órganos y personas-órgano que ejercen las funciones del Poder, sobre materias de competencia de éstos.

Asimismo, de manera didáctica, RUBIO, EGUIGUREN y BERNALES ${ }^{19}$ sostienen que es el derecho de recurrir ante las autoridades para solicitar algo que ellas podrían otorgarnos legalmente, pero a lo que no tenemos derecho cierto y actual. Aquello en lo que consiste la petición, de esta manera, puede ser o bien algo cuyo otorgamiento depende de la discrecionalidad de la autoridad, o bien algo que la autoridad puede conceder como una gracia especial.

Con relación a su naturaleza jurídica, el Tribunal Constitucional ha reconocido que el derecho fundamental de petición es uno de naturaleza mixta, toda vez que la petición puede ser de naturaleza pública o privada, según sea utilizada en el caso de la defensa de los derechos o intereses del peticionario o para la presentación de puntos de vista de interés general ${ }^{20}$.

En ese sentido, el derecho de petición se constituye así en un instrumento o mecanismo que permite a los ciudadanos relacionarse con los poderes públicos $y$, como tal, deviene en un instituto característico y esencial del Estado Democrático y Social de Derecho. Así, todo cuerpo político que se considere democrático, deberá establecer la posibilidad de la participación y decisión de los ciudadanos en la cosa pública, así como la defensa de sus intereses o la sustentación de sus expectativas, en su relación con la Administración Pública. De ese modo, las peticiones individuales o colectivas que buscan el reconocimiento de un derecho subjetivo, o en las cuales se solicite información o se formulen consultas, o que se impetre un acto graciable de la autoridad competente, el derecho en mención se constituirá en un medio ordinario para su efectiva realización ${ }^{21}$.

En lo que respecta al contenido esencial del derecho fundamental de petición, en reiterada jurisprudencia, el Tribunal Constitucional ha reconocido que tiene dos aspectos que se fundamentan en su propia naturaleza y en la especial configuración que le ha dado la Constitución: el primer aspecto es el relacionado estrictamente con la libertad reconocida a cualquier persona para formular pedidos a la autoridad; y el segundo, irremediablemente unido al anterior, es el que se refiere a recibir una respuesta de la referida autoridad, la cual, de conformidad con lo previsto por la Constitución, debe necesariamente hacerse por escrito y dentro del plazo que la ley establezca22.

De otro lado, en lo concerniente a la legitimación de los sujetos para el ejercicio del derecho fundamental de petición, en la Sentencia del Tribunal Constitucional recaída en el Expediente No. 0941-2001-AA/TC se señaló que, la legitimación activa le corresponde a cualquier persona nacional o extranjera ${ }^{23}$; y la legitimación pasiva a cualquier órgano, organismo estatal u entidad pública, y, en general, a los funcionarios o autori-

19. RUBIO CORREA, Marcial; EGUIGUREN PRAELI, Francisco y BERNALES BALLESTEROS, Enrique. Los Derechos Fundamentales en la Jurisprudencia del Tribunal Constitucional. Análisis de los artículos 1, 2 y 3 de la Constitución. Fondo Editorial de la Pontificia Universidad Católica del Perú: Lima, 2010. p. 581.

20. Sentencia del Tribunal Constitucional, recaída en el Expediente No. 1042-2002-AA/TC.

21. GARCÍA TOMA, Víctor. Op.Cit. p. 266.

22. Sentencias del Tribunal Constitucional, recaídas en los Expedientes No. 0941-2001-AA/TC y No. 1042-2002-AA/TC.

23. Cabe precisar que, respecto del ejercicio del derecho fundamental de petición por parte de personas extranjeras, en la Sentencia del Tribunal Constitucional, recaída en el Expediente No. 1042-2002-AA/TC, se indicó lo siguiente: "Así, cualquier persona natural o jurídica, nacional o extranjera puede actuar como sujeto activo en el ejercicio de dicho derecho.

Por consiguiente, los extranjeros, residualmente, pueden participar como electores y hasta candidatos en comicios vecinales, tal y conforme lo permite nuestro ordenamiento". 
dades públicas que se consideren competentes para satisfacer la pretensión.

La Ley 27444 - Ley del Procedimiento Administrativo General (en adelante, LPAG) se ha encargado de desarrollar los alcances del derecho fundamental de petición, y las modalidades a través de las cuales las personas pueden ejercerlo. De conformidad con lo expuesto en la Sentencia del Tribunal Constitucional, recaída en el Expediente No. 1042-2002-AA/TC, en nuestro ordenamiento se reconocen cinco "ámbitos de operatividad" del mencionado derecho fundamental:

(i) Petición Cívica: Se encuentra referida a la representación de un grupo indeterminado de personas o de la colectividad en su conjunto, la cual tiene por objeto la protección y promoción del bien común y del interés público, así como exponer críticas y formular sugerencias para mejorar la calidad y extensión del servicio administrativo ${ }^{24}$, a través de la exposición de la existencia de problemas generales, trabas y obstáculos normativos o viciosas prácticas administrativas que afectan el acceso ciudadanos a las entidades públicas, a su relación con los titulares o funcionarios con capacidad y decisión, etc.

Asimismo, se considera que la Petición Cívica consiste en la crítica que la persona hace del comportamiento de la autoridad, con la finalidad de lograr que su actuación se acomode al interés general ${ }^{25}$.

El artículo 108 de la LPAG ha recogido esta modalidad del derecho fundamental de petición.

(ii) Petición Informativa: Se encuentra referida a la obtención de documentación oficial contenida en los bancos informativos o registros manuales de la institución o entidad requerida (por ejemplo, datos estadísticos, dictámenes, resoluciones, etc.).

Igualmente, se considera que la Petición Informativa consiste en la solicitud por parte de la persona, de información que está en poder de la autoridad ${ }^{26}$.

(iii) Petición Consultiva: Está destinada a obtener un asesoramiento oficial (en relación con una materia administrativa concreta, puntual y específica), una colaboración instructiva acerca de las funciones y competencias administrativas o sobre los alcances y contenidos de la normatividad o reglamentos técnicos aplicables al peticionante. Con ello se consigue eliminar cualquier resquicio de duda o incertidumbre en torno a la relación administración-administrado.

De este modo, se consigue que la Administración Pública asesore, cuando esto es posible, sobre algún tema específico vinculado con sus atribuciones ${ }^{27}$. La Petición Consultiva se encuentra prevista en el artículo 111 de la LPAG.

(iv) Petición Subjetiva: Se encuentra referida a la solicitud individual o colectiva que tiene por objeto el reconocimiento administrativo de un derecho de la misma naturaleza; es decir, conlleva a la admisión de la existencia de una facultad o atribución para obrar o abstenerse de obrar y para que el peticionante haga exigible a terceros un determinado tipo de prestación o comportamiento.

La Petición Subjetiva contiene el pedido de algo a lo que ese tiene legítimo derecho, por ejemplo, que se nos empiece a pagar nuestra jubilación luego de cumplir los

24. GARCÍA TOMA, Víctor. Op.Cit. p. 270.

25. RUBIO CORREA, Marcial; EGUIGUREN PRAELI, Francisco y BERNALES BALLESTEROS, Enrique. Op.Cit. p. 589.

26. Ibid. p. 589.

27. Ibid. p. 590. 
requisitos para ello. En estos casos, si efectivamente el solicitante tiene el derecho, la autoridad debe reconocerlo sin que ella pueda decidir si lo otorga o no ${ }^{28}$.

Esta modalidad del derecho fundamental de petición, se encuentra prevista en el artículo 107 de la LPAG.

(v) Petición Gracial o de Gracia: Se encuentra referida a la obtención de una decisión administrativa a consecuencia de la discrecionalidad y libre apreciación de un ente administrativo. Esta modalidad no se sustenta en ningún título jurídico específico, sino que se atiene a la esperanza o expectativa de alcanzar una gracia administrativa. A lo sumo, expone como fundamento para la obtención de un beneficio, tratamiento favorable o liberación de un perjuicio no contemplado jurídicamente, la aplicación de la regla del merecimiento.

A través de la Petición de Gracia, a diferencia de la Petición Subjetiva, se pide a la autoridad que otorgue protección o beneficio para el cual el sujeto activo no tiene derecho y que, en consecuencia, depende de la gracia de la autoridad. Es el caso, por ejemplo, de un artista famoso que solicite una pensión de gracia para su vejez ${ }^{29}$.

La Petición de Gracia se encuentra contemplada en el artículo $112^{30}$ de la LPAG.

Precisamente, bajo esta última modalidad se ha calificado a las propuestas de Iniciativas
Privadas, de conformidad con lo previsto en el artículo 14 de la Ley Marco de Asociaciones Público-Privadas, el cual señala expresamente lo siguiente:

\section{"Artículo 14.- De la naturaleza de las ini- ciativas privadas}

(...)

Las iniciativas privadas tienen el carácter de peticiones de gracia a que se refiere el Artículo $112^{\circ}$ de la Ley $N^{\circ} 27444$, Ley del Procedimiento Administrativo General, en lo que sea pertinente. En consecuencia, el derecho del proponente se agota con la presentación de la iniciativa privada ante el Organismo Promotor de la Inversión Privada, sin posibilidad de impugnación del pronunciamiento en sede administrativa o judicial. (...)". [el subrayado es nuestro]

El señalado carácter de Petición de Gracia se mantendrá hasta que:

(i) El proyecto sea incorporado al proceso de promoción de la inversión privada y se convoque a una Oferta Pública, Licitación Pública o Concurso de Proyectos Integrales, en cuyo caso será de aplicación, según corresponda, lo dispuesto en las respectivas bases y/o en la legislación aplicable; 0 ,

(ii) Se suscriba el contrato correspondiente, en caso el proyecto se adjudique directamente por no haber terceros interesados.

Ahora bien, tomando en consideración lo desarrollado por la doctrina especializada ${ }^{31}$ y lo ex-

28. Ibid. p. 591.

29. Ibid. p. 590

30. "Artículo 112.- Facultad de formular peticiones de gracia

112.1 Por la facultad de formular peticiones de gracia, el administrado puede solicitar al titular de la entidad competente la emisión de un acto sujeto a su discrecionalidad o a su libre apreciación, o prestación de un servicio cuando no cuenta con otro título legal específico que permita exigirlo como una petición en interés particular.

112.2 Frente a esta petición, la autoridad comunica al administrado la calidad graciable de lo solicitado y es atendido directamente mediante la prestación efectiva de lo pedido, salvo disposición expresa de la ley que prevea una decisión formal para su aceptación.

112.3 Este derecho se agota con su ejercicio en la vía administrativa, sin perjuicio del ejercicio de otros derechos reconocidos por la Constitución".

31. RUBIO CORREA, Marcial; EGUIGUREN PRAELI, Francisco y BERNALES BALLESTEROS, Enrique. Op.Cit. p. 590. 
puesto en reiterada jurisprudencia del Tribunal Constitucional ${ }^{32}$, el otorgamiento de la gracia solicitada debe ejercitarse discrecionalmente, con razonabilidad, proporcionalidad y motivación. Por consiguiente, en la medida que constituye una modalidad de ejercicio del derecho fundamental de petición, la calificación de las Iniciativas Privadas como Peticiones de Gracia genera, entre otras obligaciones, una indispensable a cargo del OPIP: en caso una propuesta de proyecto de inversión bajo la modalidad de una Iniciativa Privada sea desestimada, corresponderá al OPIP competente, de manera obligatoria o necesaria, brindar al proponente una respuesta del sentido de la decisión adoptada.

Sobre el particular, considero que la obligación por parte del OPIP de brindar una respuesta al proponente no se agota en el simple o mero pronunciamiento que deniegue o rechace la propuesta formulada por el inversionista. El pronunciamiento que formule el OPIP deberá contener una motivación debida, la cual deberá abordar los fundamentos jurídicos, financieros, económicos, técnicos y/o medio ambientales, entre otros, por los cuáles se desestima la propuesta.

En efecto, con relación al pronunciamiento o decisión que resuelve una Petición de Gracia, el mencionado Tribunal Constitucional ha precisado que "la autoridad tiene la obligación de realizar todos aquellos actos que sean necesarios para evaluar materialmente el contenido de la petición y expresar el pronunciamiento correspondiente, el mismo que contendrá los motivos por los que se acuerda acceder o no a lo peticionado, debiendo comunicar lo resuelto al interesado o interesados" ${ }^{\prime \prime 3}$.
Para LUNA CERVANTES, esta precisión es de suma importancia, en la medida que el Tribunal Constitucional declara que "no es admisible jurídicamente la mera puesta en conocimiento al peticionante de la decisión adoptada por el funcionario público correspondiente", sino que se requiere de una motivación debida; al punto que sanciona con la invalidez el acto material que contiene la respuesta por "omisión de un deber jurídico claro e inexcusable" ${ }^{1 / 34}$.

Finalmente, debemos señalar que el deber de motivar debidamente la decisión adoptada por el OPIP, cuando se desestime, deniegue o rechace una propuesta de Iniciativa Privada, se encuentra recogido en diversos instrumentos que regulan el trámite y evaluación de Iniciativas Privadas. Por ejemplo, en la Directiva 004-2009-PROINVERSIÓN "Tramitación y Evaluación de Iniciativas privadas en Proyectos de Inversión", aprobada mediante Acuerdo Preinversión 278-01-2009, se señala expresamente lo siguiente:

\section{“VI. ADMISIÓN A TRÁMITE Y EVALUACIÓN} (...)

Admisión a Trámite o Rechazo de Iniciativas Privadas

(...)

6.2.2. De rechazarse la iniciativa privada, el Comité de PROINVERSION emitirá el Acuerdo correspondiente e instruirá a la Dirección de Asuntos Técnicos para que comunique su decisión al titular de la Iniciativa Privada expresando la(s) causa(s) que motiva(n) el rechazo, dentro de un plazo no mayor de cinco (5) días hábiles de recibido el acuerdo".

32. Sentencias del Tribunal Constitucional, recaídas en los Expedientes No. 0941-2001-AA/TC y No. 1042-2002-AA/TC.

33. Sentencia del Tribunal Constitucional, recaída en el Expediente No. 1042-2001-AA/TC. Sobre el particular, el Tribunal Constitucional ha señala que si bien el derecho fundamental de petición implica que la autoridad competente debe dar respuesta por escrito a una petición formulada también por escrito, no debe confundirse el contenido del pronunciamiento de la autoridad con la notificación al peticionante de las acciones desarrolladas por aquella en atención a lo solicitado, pues el contenido del pronunciamiento - a expresarse por medio de la forma jurídica administrativa adecuada - se refiere a la decisión de la Administración Pública que favorece o no lo peticionado; y la notificación se refiere más bien a una formalidad ineludible para la autoridad, utilizada para poner en conocimiento del peticionante el resultado de su petición.

34. LUNA CERVANTES, Eduardo. En: AA.VV. La Constitución Comentada. Análisis Artículo por Artículo. Una obra colectiva escrita por 117 destacados juristas del país. Gaceta Jurídica: Lima, 2005. Tomo I. p. 195. 
IV. LA DESESTIMACIÓN DE UNA INICIATIVA PRIVADA SIN UNA DEBIDA MOTIVACIÓN, CONFIGURA UNA VULNERACIÓN AL "DEBIDO PROCESO DE PROMOCIÓN DE LA INVERSIÓN PRIVADA"

El derecho fundamental al debido proceso ha sido objeto de estudio por un amplio e importante sector de la doctrina. Respecto de dicho derecho fundamental, se ha reconocido que constituye un derecho de carácter complejo; es decir, se trata de un derecho fundamental que comprende y se encuentra integrado por otros derechos fundamentales ${ }^{35}$.

Dicha posición es compartida por nuestro Tribunal Constitucional, tal como se puede apreciar de los diversos pronunciamientos contenidos en las sentencias o resoluciones ${ }^{36}$ vinculadas a procesos constitucionales, donde ha sido materia de análisis la existencia de eventual vulneración al derecho fundamental a un debido proceso.

Asimismo, en reiterada jurisprudencia, nuestro Tribunal Constitucional ha reconocido que si bien el derecho fundamental al debido proceso tiene su ámbito natural de aplicación en sede jurisdiccional, también es aplicable en el ámbito de los procedimientos administrativos ${ }^{37}$.
Sobre el particular, resulta ilustrativo lo expuesto en la Sentencia recaída en el Expediente No. 08605-2005-AA/TC, en la cual se indica lo siguiente:

"13.Evidentemente, el debido proceso y los derechos que conforman su contenido esencial están garantizados no solo en el seno de un proceso judicial, sino también en el ámbito del procedimiento administrativo. El debido procedimiento administrativo supone, en toda circunstancia, el respeto - por parte de la administración pública o privada-de todos los principios y derechos normalmente protegidos en el ámbito de la jurisdicción común o especializada, a los cuales se refiere el artículo $139^{\circ}$ de la Constitución (STC 4289-2004-AA/TC)". (el resaltado es nuestro)

Por consiguiente, tal como lo hemos desarrollado en un trabajo anterior ${ }^{38}$, es posible sostener la existencia de un derecho a un debido procedimiento administrativo, como manifestación del derecho fundamental al debido proceso, el cual supone una garantía de los derechos del administrado frente a las actuaciones de la Administración Pública, las que deberán llevarse a cabo atendiendo a las disposiciones o reglas previamente estableci-

35. FERNANDEZ SEGADO, Francisco. El sistema constitucional español. DYKINSON: Madrid, 1992. p.282; BUSTAMANTE ALARCÓN, Reynaldo. Derechos fundamentales y proceso justo. ARA Editores: Lima, 2001. p.342; MONROY GALVEZ, Juan. En: AA.VV. La constitución comentada. Análisis artículo por artículo. Gaceta Jurídica: Lima, 2006. Tomo II. p. 497.

36. En efecto, entre tales pronunciamientos podemos hacer referencia a aquellos contenidos en las Sentencias del Tribunal Constitucional, recaídas en los Expedientes No. 5194-2005-PA/TC, No. 07289-2005-PA/TC, y No. 06149-2006PA/TC y No. 6662-2006-PA/TC (procesos acumulados). Precisamente, en esta última resolución se ha indicado lo siguiente:

"37. Se ha señalado, igualmente, que dicho derecho comprende, a su vez, diversos derechos fundamentales de orden procesal y que, en ese sentido, se trata de un derecho "continente". En efecto, su contenido constitucionalmente protegido comprende una serie de garantías, formales y materiales, de muy distinta naturaleza, cuyo cumplimiento efectivo garantiza que el procedimiento o proceso en el cual se encuentre comprendida una persona, pueda considerarse como justo".

37. Entre tales pronunciamientos podemos hacer referencia a aquellos contenidos en las Sentencias del Tribunal Constitucional, recaídas en los Expedientes No. 2659-2003-AA/TC, No. 03741-2004-AA/TC, No. 1690-2005-PA/TC, No. 07289-2005-PA/TC, No. 08105-2005-PA/TC, No. 05085-2006-PA/TC, No. 06149-2006-AA/TC y No. 6662-2006PA/TC (procesos acumulados) y No. 08865-2006-PA/TC.

38. Cfr. LEÓN PACHECO, José Francisco. La aplicación del principio de pertinencia probatoria en el ejercicio de la función supervisora de los organismos reguladores. Pedir o no pedir... he ahí el dilema. En: Revista Actualidad Jurídica. Febrero 2011, Tomo 207. Gaceta Jurídica. p. 186. 
das en la Constitución, las leyes y, en general, en el ordenamiento jurídico vigente ${ }^{39}$.

Precisamente, el derecho a un debido procedimiento administrativo se encuentra reconocido en nuestro ordenamiento jurídico en el numeral 1.2. del Artículo IV del Titulo Preliminar de la Ley 27444 - Ley del Procedimiento Administrativo General (en adelante, LPAG), como un principio que regula la actuación de toda la Administración Pública en los procedimientos administrativos.

Dicha disposición legal establece expresamente lo siguiente:

\section{"Artículo IV.- Principios del procedimiento administrativo}

1. El procedimiento administrativo se sustenta fundamentalmente en los siguientes principios, sin perjuicio de la vigencia de otros principios generales del Derecho Administrativo:

\section{(...)}

1.2. Principio del debido procedimien-

to.- Los administrados gozan de todos los derechos y garantías inherentes al debido procedimiento administrativo, que comprende el derecho a exponer sus argumentos, a ofrecery producir pruebas y a obtener una decisión motivada y fundada en derecho. La institución del debido procedimiento administrativo se rige por los principios del Derecho Administrativo. La regulación propia del Derecho Procesal Civil es aplicable sólo en cuanto sea compatible con el régimen administrativo".
En tal sentido, atendiendo a lo previsto en la disposición legal citada, es posible reconocer, entre otros, al derecho a obtener una decisión motivada y fundada jurídicamente, como parte de los derechos que componen el derecho a un debido procedimiento administrativo.

En lo que específicamente se refiere a la debida motivación de las decisiones de la Administración Pública, aquella ha sido reconocida como un requisito de validez de los actos administrativos ${ }^{40}$, cuya formalidad y contenido mínimo exigible se encuentran precisados en el artículo 6 de la LPAG. En consecuencia, las decisiones de la Administración Pública deben estar necesariamente acompañadas de una adecuada motivación que contenga una clara exposición de: i) los hechos que motivan el pronunciamiento; ii) la interpretación que se ha hecho de las normas aplicables y; iii) el razonamiento realizado por la entidad para sustentar el pronunciamiento.

Con relación a los vicios en la motivación, el Tribunal Constitucional ${ }^{41}$ ha reconocido que pueden deberse a la inexistencia total de justificación de la decisión o la presencia de una que sólo es aparente, a la falta de motivación interna de razonamiento, a deficiencias en la motivación externa, a la justificación insuficiente y a la justificación sustancialmente incongruente ${ }^{42}$.

Por tanto, en caso el OPIP competente omita una debida motivación al desestimar una Iniciativa Privada, incurriendo en los vicios antes señalados, se configurará una vulneración al derecho al "debido proceso de promoción de la inversión privada" (reconocido expresamente como tal en la Sentencia del Tribunal Constitucional, recaída en el Expediente No. 01387-

39. Cfr. Sentencias del Tribunal Constitucional, recaídas en los Expedientes No. 03741-2004-AA/TC, No. 08957-2006PA/TC y No. 0091-2005-PA/TC.

40. "Artículo $3^{\circ}$.- Requisitos de validez de los actos administrativos

Son requisitos de validez de los actos administrativos: (...)

4. Motivación.- El acto administrativo debe estar debidamente motivado en proporción al contenido y conforme al ordenamiento jurídico".

41. Sentencias del Tribunal Constitucional, recaídas en los Expedientes No. 1744-2005-AA/TC, No. 3943-2006-PA/TC, y No. 0728-2008-PHC-TC.

42. Sentencia del Tribunal Constitucional, recaída en el Expediente No. 0728-2008-PHC-TC. 
2009-PA/TC), aplicable al momento de tramitar una propuesta de proyecto de inversión privada bajo el mencionado mecanismo o modalidad para la participación o promoción de la inversión privada.

Finalmente, si bien algunos autores ${ }^{43}$ sostienen que, atendiendo a su calificación expresa como Peticiones de Gracia, el pronunciamiento que rechace una Iniciativa Privada no podría ser objeto de impugnación en la vía administrativa ni judicial; considero que, en el caso específico de aquellos casos, en los que se haya emitido un pronunciamiento que omita una debida motivación, vulnerándose así el derecho a un debido procedimiento administrativo en un proceso de promoción de la inversión privada, el proponente o titular de la Iniciativa Privada rechazada se encontrará habilitado para cuestionar dicha decisión en la vía judicial correspondiente.

43. Cfr. VIVANCO DEL CASTILLO, Tábata y VILLANUEVA LLAQUE, Augusto. Op.Cit. p.307. Asimismo, MORI COCKBURN, Javier. Op.Cit. pp. 239-240. 